\title{
Characterization of Escherichia coli and other Enterobacteriaceae in producer-distributor bulk milk
}

\author{
V. Ntuli, P. M. K. Njage, and E. M. Buys ${ }^{1}$ \\ Department of Food Science, University of Pretoria, Private Bag X20, Hatfield, Pretoria 0028, South Africa
}

\begin{abstract}
The current study was undertaken to characterize Escherichia coli and other Enterobacteriaceae in raw and pasteurized producer-distributor bulk milk (PDBM). A total of 258 samples were collected from purchase points in 8 provinces in South Africa. The samples were tested for antibiotic residues, phosphatase, total aerobic bacteria, coliforms, and E. coli counts. Matrixassisted laser desorption/ionization time-of-flight mass spectrometry was used for identification of isolates. Escherichia coli isolates were characterized for virulence factors, antimicrobial resistance, serotypes, and presumptive E. coli O157:H7. Antibiotic residues and alkaline phosphatase were detected in $2 \%$ of both raw and pasteurized PDBM $(\mathrm{n}=258)$ and $21 \%$ pasteurized PDBM ( $\mathrm{n}=104)$ samples, respectively. A total of 729 isolates belonging to 21 genera and 59 species were identified. Escherichia coli, Enterobacter cloacae, Klebsiella oxytoca, and Raoultella ornithinolytica were the most abundant species. Spoilage Enterobacteriaceae species exceeded $50 \%$ of the total isolates. Escherichia coli was detected and isolated from $36 \%$ of the milk samples. Thirty-one E. coli isolates harbored virulence genes stx1/stx2 and 38\% $(\mathrm{n}=121)$ were presumptive O157:H7. The prevalence of samples with presumptive shigatoxin producing E. coli was $10 \%$. Antimicrobialresistant E. coli isolates were detected in $70 \%$ of the milk samples with $36 \%$ of stx1/stx2 positive E. coli showing multi-drug resistance. Information obtained from the study will be used for modeling the public health risk posed by milkborne pathogens in PDBM, which in many cases is consumed by poor and vulnerable members of the population.
\end{abstract}

Key words: producer-distributor milk, Enterobacteriaceae, Escherichia coli, shigatoxin, antibiotic resistance

Received May 5, 2016.

Accepted August 18, 2016.

${ }^{1}$ Corresponding author: Elna.Buys@up.ac.za

\section{INTRODUCTION}

Members of the Enterobacteriaceae family have been implicated in many safety and spoilage problems (Baylis et al., 2011). Enterobacteriaceae can enter an inadequately handled dairy chain and cause enzymatic breakdown of proteins or lipids, instigating spoilage that contributes to substantial economic losses and waste (Baylis et al., 2011). In addiiton, some Enterobacteriaceae have emerged as potential opportunistic pathogens due to acquisition (via horizontal gene transfer among different strains or bacterial species) of virulence and antibiotic resistance factors carried on mobile genetic elements such as plasmids, transposons, and bacteriophages (Baylis et al., 2011). Enterobacteriaceae including Shiga toxin-producing Escherichia coli (STEC), Salmonella spp., and Yersinia enterocolitica have been detected frequently in milkborne disease outbreaks (Jayarao and Henning, 2001; Oliver et al., 2009).

The members of Enterobacteriaceae that are most implicated in serious fatalities and illnesses in most foodborne outbreaks, including milkborne disease outbreaks around the world, include several E. coli pathotypes. Numerous outbreaks associated with enteropathogenic E. coli and enterohemorrhagic E. coli (EHEC) in milk and other foods have been reported recently (Oliver et al., 2009; EFSA-ECDC, 2012; EFSA, 2015). Pathogenic $E$. coli can cause disease in humans and animals due to an assortment of virulence factors (Beutin et al., 2004). One such E. coli pathotype that has been reported in milk outbreaks is the STEC, which is a causative agent of hemorrhagic colitis and hemolytic uremic syndrome (Oliver et al., 2009). The main route of infection with STEC in humans is via consumption of contaminated foods, including milk, which is commonly associated with asymptomatic dairy cattle reservoirs (Iweriebor et al., 2015). Important STEC virulence encoding genes, which make E. coli an insidious threat to food safety, are the phage-encoded Shiga toxin genes (stx1 and stx2) and the intimin gene (eae). Shiga toxins inhibit protein synthesis of host cells and lead to cell death, whereas the intimin gene mediates colonization. Enterohemolysin gene $(e h x A)$ encodes for cell lysis whereby the membranes of target cells 
including erythrocytes, leukocytes, and renal tubular cells are perforated (Kerényi et al., 2005). The most implicated STEC in human illnesses associated with foods is the E. coli serotype O157:H7. However, current studies have revealed the global emergence of non-O157 STEC serotypes (O111, O26, O145, and O103) associated with foodborne outbreaks (Constantiniu, 2002). Recent milkborne outbreaks associated with STEC O157:H7 have been reported in 2005, 2006, and 2007 in the United States (CDC, 2008), 2008 in Germany, and 2012 in Finland (EFSA, 2015). The presumptive route of O157 STEC in milk is through fecal contamination during milking and also direct shedding from infected udder (King et al., 2007).

The potential occurrence of pathogenic E. coli in food is not the only risk. In addition to the outbreaks, treatment of $E$. coli infections is now threatened by a rapid evolution of antimicrobial-resistant strains (Da Silva and Mendonça, 2012). Resistance of E. coli and other bacteria to antimicrobials has been reported worldwide and is one of the most pressing public health issues of our time. Inappropriate selection, intensive usage, and abuse of antimicrobials may have led to antimicrobial resistance in bacteria (Da Silva and Mendonça, 2012). Concerns have been raised about the potential spread of antibiotic resistance genes such as $\beta$-lactamase from food animal products such as milk to humans through the food supply (Iweriebor et al., 2015). Research has also revealed an association between resistance to drugs and virulence capacity (Da Silva and Mendonça, 2012). Acquisition of antibiotic resistance and virulence factor determinants in $E$. coli can be through lateral gene transfer in the environment or in the human and animal gut. The determinants can be found either inserted on the same plasmid or separately on bacterial chromosomal DNA and plasmids. These determinants might be co-selected by antibiotic selection pressure, hence exacerbating the risk posed by $E$. coli to food safety (Da Silva and Mendonça, 2012). Outbreaks of antibiotic-resistant pathogenic bacteria have been reported recently in different foods (CDC, 2013).

Most milkborne disease outbreaks has been implicated to originate from consumption of raw milk at farms or milk that is sold directly from the producerdistributor or from farm to consumer in bulk tanks (Jayarao et al., 2006; Oliver et al., 2009; EFSA-ECDC, 2012; EFSA, 2015). However, few reports are available on outbreaks from pasteurized milk (CDC, 2008). In developing countries, no epidemiological statistics are available on milkborne outbreaks even though the sale of producer-distributor bulk milk (PDBM) is common. Suffice to say, in developing countries, the direct sale of milk to consumers plays an important role as it contributes to food security and nutrition as well as social and economic benefits (Swai and Schoonman, 2011). South Africa (SA) is one such country where the dairy industry is characterized by a growing number of producer-distributors selling milk directly from producers to consumers in the form of bulk tank milk. The milk is mostly consumed by poor and vulnerable members of the population.

Recent reports have highlighted microbiological inadequacy in the quality of PDBM sold in SA. However, these studies have not characterized spoilage microbiota and possible pathogens in the milk. Therefore, this study focuses on characterization of $E$. coli and other Enterobacteriaceae in PDBM. It is envisaged that the information from this research will be useful in modeling the risk from pathogenic E. coli in retail PDBM and the proposal of most potentially effective mitigation efforts toward enhanced food security through reduction in incidences of milkborne zoonosis.

\section{MATERIALS AND METHODS}

\section{Milk Sample Collection}

Sampling of PDBM was done from purchase points according to ISO standards (ISO, 1997) within 8 different geographical provinces $(\mathbf{P 1}-\mathbf{P} 8)$ in SA by environmental health officers. An average of 30 retail bulk milk samples were collected per province adding up to a total of 258 samples (154 raw and 104 pasteurized). Each of the 500-mL milk samples was collected in sterile containers, which were kept chilled and were analyzed at Lactolab Irene, Pretoria, SA, within $48 \mathrm{~h}$ of collection.

\section{Antibiotic Residue and Phosphatase Test}

Alkaline phosphatase (ALP) test was carried out using a PhosphatesmoMI test kit (Macherey-Nagel GmbH \& Co. KG, Düren, Germany). A CMT Antibiotic test kit (code number 611683, Chr Hansen, Hørsholm, Denmark) was used to detect the presence of antibiotic residues in the milk.

\section{Microbiological Analyses}

For enumeration of total aerobic plate count, E. coli, and coliforms, 3M Petrifilm (St. Paul, MN) was used. Total plate count was carried out on 3M Petrifilm Aerobic Count plates, and 3M Petrifilm E. coli/coliform plates were used to detect and enumerate $E$. coli and coliforms $\left(37 \pm 0.5^{\circ} \mathrm{C}\right.$ for $\left.24 \pm 2 \mathrm{~h}\right)$. Isolation and characterization of E. coli, coliforms, and other Enterobacteriaceae was carried out at the Department of Food Science, University of Pretoria. Five colonies from each E. coli/coliform Petrifilm plate were selected based on 
color, size, and morphology. Colonies were then streaked and purified on nutrient agar (Oxoid, Basingstoke, UK; $18-24 \mathrm{~h}$ at $\left.37 \pm 0.5^{\circ} \mathrm{C}\right)$. Eosin methylene blue and sorbitol MacConkey agar (Oxoid) were used for further presumptive confirmation of $E$. coli and coliforms (37 $\pm 0.5^{\circ} \mathrm{C}$ for $24 \pm 2 \mathrm{~h}$ ). Potassium hydroxide $(3 \%)$ was used for Gram stain reactions (Romano et al., 2005).

\section{Identification and Characterization of the Bacterial Isolates}

A method by Mazzeo et al. (2006) and Pinto et al. (2010) was used for identification of the isolates. Bacterial cultures, consisting of 8 wells per isolate, in nutrient agar were extracted and transferred directly to the matrix-assisted laser desorption/ionization time-offlight (MALDI-TOF) steel-polished target plate and overlaid with $\alpha$-cyano-4 hydroxycinnamic acid matrix (Bruker, Germany) according to manufacturer instructions (Bruker Daltonics, Bremen, Germany). Mass spectra were generated with the Microflex LT mass spectrometer operated by the MALDI-Biotyper automation control and recorded by Flex Control software (Bruker Daltonics). Three hundred shots per sample spot were acquired using the instrument settings consisting of linear positive mode, $60 \mathrm{~Hz}$ laser frequency, $20 \mathrm{kV}$ acceleration voltage, $16.7 \mathrm{kV}$ IS2 voltage, 170 ns extraction delay, and 2,000 to $20,137 \mathrm{~m} / \mathrm{z}$ range as recommended for bacterial identification. The peak lists generated were used to directly obtain matches against the reference library (SARAMIS database) using the integrated pattern matching algorithm of the software (MALDI-TOF 3.0, Bruker Daltonics). The MALDI Biotyper 3.0 software was used to analyze raw spectra of the bacterial isolates, with default settings. The software compares acquired sample spectra to reference spectra in the provided SARAMIS database and compiles a list of best matching database records. The MALDI-TOF identification results were recorded as score values and used to determine the identity of the organism as proposed by the manufacturer. A score $<1.700$ indicates no identification, 1.700 to 1.999 indicate identification to genus level, $\geq 2.000$ denotes identification to genus and probable species, and scores above 2.3 indicate highly probable species identification (Cherkaoui et al., 2010).

\section{Antimicrobial Susceptibility Testing of E. coli Isolates}

The Kirby-Bauer disk diffusion method (Sayah et al., 2005) was used to determine antibiotic sensitivity profiles of the isolated $E$. coli. A total of 11 antimicrobial agents (oxytetracycline, cephalothin, nitrofurantoin, amoxicillin, ampicillin, neomycin, amikacin, gentamicin, nalidixic acid, chloramphenicol, norfloxacin; Mast Diagnostics, Bootle, UK) were chosen on the basis of common usage for treatment in the medical and agricultural fields or as feed additives to promote growth in animals (Sayah et al., 2005). Isolates were categorized as susceptible or resistant to each antimicrobial agent (CLSI, 2011).

\section{Serotyping}

Serotyping of the E. coli isolates was performed by agglutination tests using polyvalent antisera (Antiserum E. coli Trivalent III; Bio-Rad, Paris, France) against 11 common $\mathrm{O}$ antigens: O111, O55, O26, O114, O124, O142, O125, O126, O128, O86, and O127.

\section{Detection of Virulence Genes in E. coli}

Multiplex real-time PCR was used to detect virulence factors, Shiga toxin 1 (stx1), Shiga toxin 2 (stx2), and intimin (eae), in E. coli isolates. The thermocycler (C1000 Touch ThermalCycler CFX96TM Real Time System, Bio-Rad, Hercules, CA) and software (CFX 127 Manager IDE, Bio-Rad) were set up for analysis using iQ-Check STEC VirX catalog \#128 357-8139 (Bio-Rad; Aijuka et al., 2015).

\section{Presumptive Detection of Shiga Toxin E. coli 0157:H7}

Presumptive detection of E. coli $\mathrm{O} 157: \mathrm{H} 7$ was carried out using 3 selective media: BBL CHROMagar O157 agar (CHROMagar, Paris, France) with cefixime-tellurite (CT) selective supplement (Fluka Analytical); BBL CHROMagar STEC with STEC ST162(S) supplement (CHROMagar Paris France); and Sorbitol MacConkey Agar (Merck, SA) supplemented with CT. Escherichia coli isolates were incubated at $37 \pm 0.5^{\circ} \mathrm{C}$ for $24 \mathrm{~h} \pm 2$ h. Escherichia coli O157:H7 (ATCC 35150) and E. coli ATCC (25922) were used as a positive and negative control, respectively.

\section{Statistical Analysis}

The data were analyzed with STATA version 11 (StataCorp, College Station, TX). Chi-squared test ( $P$ $<0.05)$ was used to test for significant differences in E. coli, coliforms, and total aerobic counts between raw and pasteurized milk samples. Two-sided Fisher's exact test was used to test for correlation between virulence factor and antibiotic resistance capacity. Analyses of variance (1 way) was performed to test for significant differences in antibiotic resistance patterns of $E$. coli 
isolated from PDBM in different provinces at $95 \%$ confidence interval. Raw spectra of the E. coli, Serratia liquefaciens, and Klebsiella oxytoca strains were analyzed using MALDI Biotyper 3.0 software to determine the association (clustering) of the isolates with source province/region. Cross-wise minimum spanning (MSP) tree matching was used to create a dendrogram. Similar MSP result in a high matching score value. Each MSP is matched against all MSP of the analyzed set. The list of score values was used to calculate normalized distance values between the analyzed species, resulting in a matrix of matching scores. The visualization of the respective relationship between the MSP was displayed in a dendrogram using the standard settings of the MALDI Biotyper 3.0 software (Dubois et al., 2010). Distance values in a dendrogram were relative and normalized to a maximal value of 10 . Species with distance levels under 1.5 have been described as reliably classified into distinct strains (Sauer et al., 2008).

\section{RESULTS AND DISCUSSION}

\section{Total Plate Count, Coliforms, and E. coli Counts in Retail PDBM}

A significant difference was found between raw and pasteurized milk $(P<0.05)$ in mean log counts of total plate count, coliforms, and E. coli (Figure 1). Total aerobic plate count, coliforms, and E. coli counts for raw milk ranges were 3.4 to $6,2.4$ to 2.7 , and 2 to 2.1 $\log \mathrm{cfu} / \mathrm{mL}$, respectively (Figure 1a). Prevalence of raw milk samples above SA national standards [SA, 2001, Act (54), (1972)] were 42, 88, and $68 \%$ for E. coli, coliforms, and total aerobic plate counts, respectively. Our results on microbial counts from raw PDBM, where more than $60 \%$ of the sample were above national standard, were consistent with previous studies carried out in SA (Lues et al., 2003; O'Ferrall-Berndt, 2003; Lues et al., 2010) and concur with studies in other countries, Torkar and Teger (2008) in Slovenia, Pyz-Łukasik et al. (2015) in Poland, and Van Kessel et al. (2004) in the United States. These studies highlighted animal and equipment cleanliness, feeding and housing strategies, rinsing water for milking machine and milking equipment washing, mastitis in animals, milk transportation, and storage conditions as reasons for high microbial counts in raw milk. High prevalence of coliforms and $E$. coli in raw milk is a cause of concern due to its association with contamination of fecal origin and the consequent risk of enteric pathogenic organisms in food. Total aerobic plate counts, coliforms, and E. coli counts for pasteurized milk ranges were 2.2 to $4.8,0$ to 2.5 , and 0 to $2 \log \mathrm{cfu} / \mathrm{mL}$, respectively (Figure $1 \mathrm{~b}$ ). The presence of high aerobic plate counts in pasteur- ized milk can be attributed to cross-contamination; however, the issue of some thermoduric microorganisms that are reported to resist heat treatment in food cannot be ignored (Mercer et al., 2015). Twenty-one percent of pasteurized milk samples were positive for ALP. The presence of ALP can be due to ineffective pasteurization or poor milk handling after pasteurization. Conversely, bacterial counts greater than $1.2 \times$ $10^{7} \mathrm{cfu} / \mathrm{mL}$, as experienced in our study, can contribute sufficient microbial ALP that cause a false positive ALP test (Rankin et al., 2010). Again, ALP reactivation also results in a positive ALP test (Whitaker et al., 2003). Microbiological counts in $60 \%$ of the milk samples exceeded SA regulatory standards, which suggests the need to assess public health risks posed to consumers by retail PDBM in the country.

\section{Identification and Characterization of Bacterial Species}

A total of 729 Enterobacteriaceae and other bacterial isolates were detected and identified from 258 PDBM samples. The isolates belonged to 21 genera and 59 species. Prevalence of the dominant Enterobacteriaceae species isolated from raw and pasteurized PDBM (coded 1-59) is depicted in Table 1, and their distribution in raw and pasteurized PDBM in the respective provinces is presented in Figure 2. Raw and pasteurized retail bulk milk samples from all 8 provinces were contaminated with a wide diversity of Enterobacteriaceae species. More than $50 \%$ of the Enterobacteriaceae isolated and detected in our study were spoilage psychrotrophic microbiota. Pseudomonas spp. was the dominant psychrotrophic bacteria in all the provinces. A commercially important characteristic of psychrotrophs that were isolated in this study is their ability to grow at low temperatures $\left(3-7^{\circ} \mathrm{C}\right)$ and release of enzymes that hydrolyze and use large protein molecules and lipids for growth, ultimately causing milk spoilage (Ledenbach and Marshall, 2010). The released enzymes are heat stable and are not inactivated by pasteurization or by other heat treatments and may continue to degrade milk and its products, even when the bacterium is destroyed (Ledenbach and Marshall, 2010).

The most prevalent Enterobacteriaceae species from PDBM, in decreasing order, were E. coli, Raoultella ornithinolytica, K. oxytoca, E. cloacae, E. asburiae, Serratia liquefaciens, and Hafnia alvei. These bacteria were also the spoilage microbiota isolated in high numbers in food products as by Doulgeraki et al. (2011). The Enterobacteriaceae are also considered as opportunistic pathogens although their implication in diarrheal diseases is not clear with the exception for E. coli pathotypes. More so, Enterobacteriaceae species in other 
studies have been noted to harbor antibiotic resistance and multi-drug resistance capacities (Miranda et al., 2008). Coque et al. (2008) reported Enterobacteriaceae as reservoirs of extended-spectrum $\beta$-lactamases in bulk milk environments. Raoultella ornithinolytica were the most prevalent species in pasteurized PDBM samples (Table 1). Most reports of $R$. ornithinolytica (formerly Klebsiella ornithinolytica) were associated with incidences of food poisoning (Lin et al., 2012). Raoultella ornithinolytica has histamine-producing capabilities, due to $h d c$ genes, which encode histidine decarboxylase (Lin et al., 2012). Few studies are available on this bac-
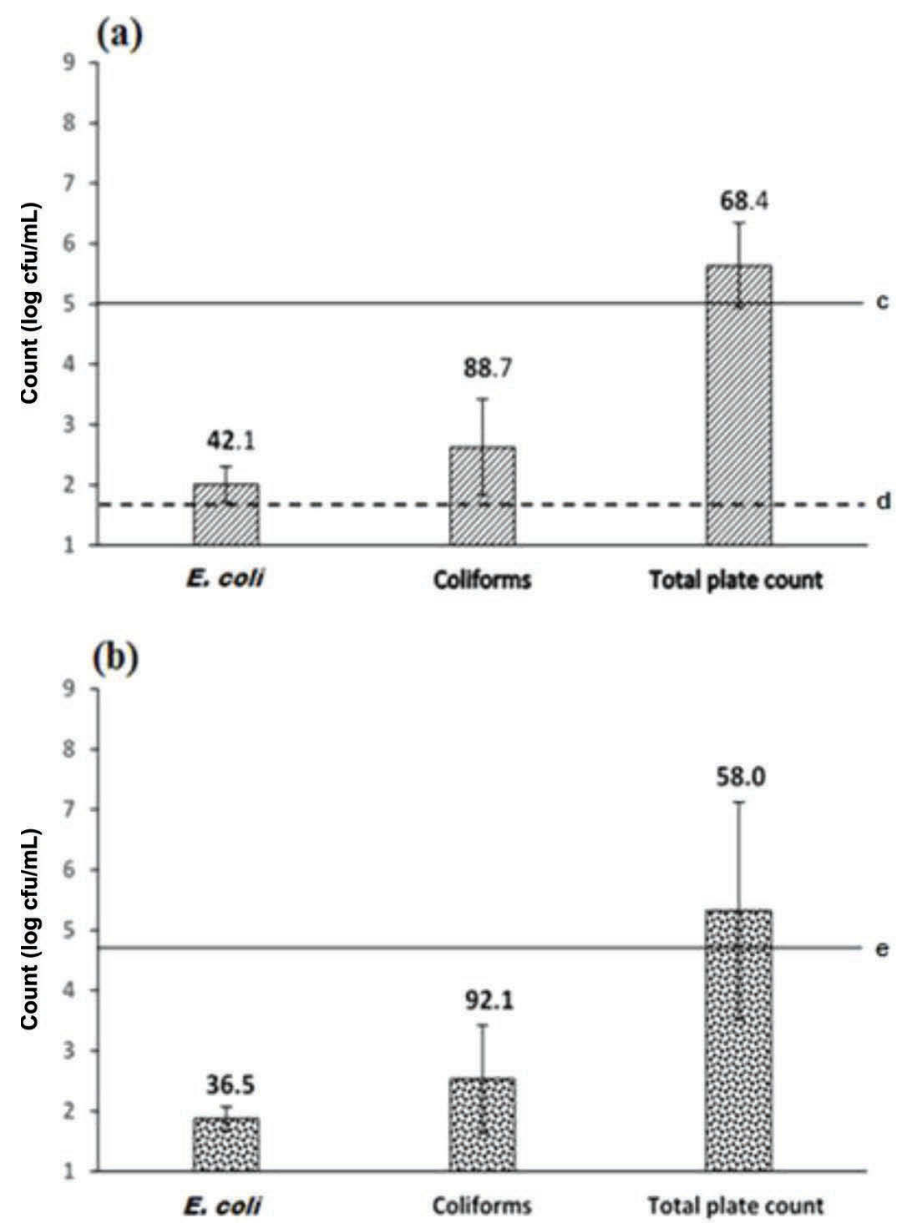

Figure 1. Mean Escherichia coli, coliform, and total aerobic plate count $(\log \mathrm{cfu} / \mathrm{mL})$ for raw bulk milk (a) and pasteurized bulk milk (b) from producer-distributors in 8 provinces in South Africa. $\mathrm{n}=258$. Solid and broken horizontal lines, designated (c) and (d) on the graph, represent maximum limit for total plate count and coliforms in raw milk, respectively. The solid line designated (e) represents the maximum limit for total plate count in pasteurized milk. Numbers above the graphs represent percentage of samples above the Foodstuffs, Cosmetics and Disinfectants Act (1997) limit for raw milk (a) and pasteurized milk (b). Coliforms should not be detected in pasteurized milk, and E. coli should not be detected in raw or pasteurized milk. Error bars represent SD. teria in milk and its products, and the real importance of $R$. ornithinolytica as a food spoilage organism or an enteric pathogen is underestimated (Lin et al., 2012). Detection of S. liquefaciens, $K$. oxytoca, and $H$. alvei in our study is of commercial significance in milk. Their presence in milk has not only been linked to undesirable alteration in appearance and flavors but also to residual activity of enzymes such as proteases, which have been associated with gelation of milk and coagulation of milk proteins during storage (Nornberg et al., 2010). We identified 6 different species of the genus Enterobacter from PDBM; however, Enterobacter cloacae and Enterobacter asburiae were detected at higher prevalence. Enterobacter cloacae and E. asburiae are emerging opportunistic pathogens causing nosocomial infections and are frequently detected in infant formula milk (Boerlin et al., 2001).

More diverse species were isolated in pasteurized milk than raw milk in this study. Out of the recorded 59 species, 19 were isolated from pasteurized milk only, whereas 10 were obtained from raw milk only, and a total of 30 species were common to both (Figure 2). The species of the organisms that were exclusively in pasteurized milk (which belonged to the following genera: Acinetobacter, Aeromonas, Buttiauxella, Citrobacter, Pseudomonas, Raoultella, and Serratia) are predominantly waterborne microorganisms. This suggests a potential cross-contamination from the processing environment arising from water aerosols and improperly cleaned processing and handling equipment (Eneroth et al., 2000). In addition, the postprocess contamination can arise from multi-species biofilms established in processing equipment forming major reservoirs for contamination (Chmielewski and Frank, 2003). Serratia liquefaciens and $K$. oxytoca were found in all milk samples from all the 8 provinces, whereas $12 \%$ of the species were isolated from at least $78 \%$ of the samples (Figure 3).

We also identified Yersinia enterocolitica in 12 out of 258 producer-distributor milk samples. Two out of 12 isolates were isolated from 2 pasteurized PDBM samples. Yersinia enterocolitica has been reported as an important public health hazard (Jayarao and Henning, 2001; Jayarao et al., 2006; Oliver et al., 2009) and has been frequently isolated in milkborne outbreaks in the United States and Europe (Oliver et al., 2009; EFSA, 2015). In the United States, Jayarao and Henning (2001) carried out a survey and reported 8 pathogenic Y. enterocolitica isolated from 131 bulk tank milk samples. We however did not test the virulence capacity of $Y$. enterocolitica strains identified in the present study. Important to note is that $Y$. enterocolitica can also resist heat treatment and is able to grow to large numbers below $15^{\circ} \mathrm{C}$ (refrigeration temperatures), which makes 
contaminated milk a significant health risk (Jayarao and Henning, 2001).

\section{Characterization of E. coli}

Escherichia coli was isolated from 36\% $(\mathrm{n}=258)$ of all the samples, with more raw milk samples (59\%) testing positive for E. coli than pasteurized milk (40\%; Figure 4). Only milk samples from 2 provinces were negative for E. coli. All 121 E. coli isolates tested negative for the 11 tested serotypes. Van Kessel et al. (2004) reported that presence of $E$. coli in raw milk can be via intramammary secretion or via fecal contamination of udder or milking equipment.

In the present study, $2 \%(\mathrm{n}=258)$ of PDBM samples tested positive for antibiotic residues. The risk of exposure to antimicrobial residues in milk has previously been reported (Kurwijila et al., 2006). Studies have reported a significant association between veterinary antibiotic residue in animal products and obesity in humans (Riley et al., 2013). However, there are dis- agreements when it comes to the association between antimicrobial residue in food and subsequent development of resistant by bacteria. Antimicrobial-resistant $E$. coli isolates were detected in more than $70 \%$ of the milk samples. Out of the 121 isolates tested, $73 \%$ showed resistance to at least one of the 11 antibiotics (Table 2). Resistance to antibiotics in $E$. coli from provinces P2 and P7 was significantly higher $(P<0.05)$ than in all the other 4 provinces. A higher number of isolates were resistant to cephalothin and susceptible to nalidixic acid. Studies around the world on E. coli from different sources have also identified high resistance to the antimicrobial agent cephalothin (Erskine et al., 2002; Schroeder et al., 2002; Sayah et al., 2005). Cephalothin is a cephalosporin that is not used in food animals as a feed additive or as a medicine (Sayah et al., 2005). However, high resistance to cephalothin may be attributed to cross-resistance, which develops through using other cephalosporins (Prescott et al., 2000; Sayah et al., 2005). Increased susceptibility of drugs such as nalidixic acid and norfloxacin that we noted in the

Table 1. Prevalence of dominant Enterobacteriaceae and other bacterial species isolated from raw (RM) and pasteurized $(\mathrm{PM})$ producer-distributor bulk milk in South Africa $(\mathrm{n}=258)^{1}$

\begin{tabular}{|c|c|c|c|c|}
\hline $\begin{array}{l}\text { Species } \\
\text { code }\end{array}$ & Species name & $\begin{array}{l}\mathrm{RM} \\
(\%)\end{array}$ & $\begin{array}{l}\mathrm{PM} \\
(\%)\end{array}$ & $\begin{array}{c}\text { Total number } \\
\text { of isolates }\end{array}$ \\
\hline 3 & Acinetobacter guillouiae & 0.6 & 0.5 & 4 \\
\hline 13 & Buttiauxella agrestis & - & 2.3 & 5 \\
\hline 14 & Buttiauxella gaviniae & 0.4 & 1.9 & 6 \\
\hline 15 & Buttiauxella noackiae & - & 3.2 & 7 \\
\hline 17 & Citrobacter braakii & 3.3 & 3.2 & 23 \\
\hline 18 & Citrobacter freundii & 2.1 & 2.3 & 15 \\
\hline 21 & Escherichia coli & 22.8 & 5.6 & 121 \\
\hline 23 & Enterobacter amnigenus & 3.1 & 4.2 & 24 \\
\hline 24 & Enterobacter asburiae & 7.5 & 3.2 & 43 \\
\hline 25 & Enterobacter cloacae & 7.5 & 7.4 & 52 \\
\hline 26 & Enterobacter kobei & 0.8 & 1.4 & 7 \\
\hline 27 & Enterobacter ludwigii & 2.5 & 1.4 & 15 \\
\hline 28 & Ewingella americana & 0.4 & 1.4 & 5 \\
\hline 29 & Hafnia alvei & 4.4 & 14 & 52 \\
\hline 30 & Klebsiella oxytoca & 10.2 & 9.7 & 70 \\
\hline 31 & Klebsiella pneumonia & 2.9 & 0.9 & 16 \\
\hline 33 & Kluyvera intermedia & 1 & 0.9 & 7 \\
\hline 35 & Pantoea agglomerans & 1.5 & 0.9 & 9 \\
\hline 36 & Proteus mirabilis & 0.4 & - & 2 \\
\hline 37 & Proteus vulgaris & 0.2 & 0.5 & 2 \\
\hline 39 & Pseudomonas aeruginosa & 0.2 & 0.5 & 2 \\
\hline 43 & Pseudomonas fluorescens & 0.2 & 1.4 & 4 \\
\hline 47 & Pseudomonas lundensis & 0.4 & - & 2 \\
\hline 48 & Pseudomonas nitroreducens & - & 0.9 & 2 \\
\hline 52 & Rahnella aquatilis & 0.8 & 2.3 & 9 \\
\hline 53 & Raoultella ornithinolytica & 16.1 & 17.1 & 114 \\
\hline 54 & Raoultella terrigena & 0.4 & 0.5 & 3 \\
\hline 55 & Serratia fonticolla & 0.4 & - & 2 \\
\hline 56 & Serratia liquefaciens & 6.3 & 8.3 & 48 \\
\hline 57 & Serratia marcescens & 1.5 & 1.9 & 11 \\
\hline 58 & Stenotrophomonas maltophilia & 0.2 & 0.5 & 2 \\
\hline \multirow[t]{2}{*}{59} & Yersinia enterocolitica & 1.7 & 1.9 & 12 \\
\hline & Total number of isolates & 479 & 216 & 697 \\
\hline
\end{tabular}

${ }^{1} \mathrm{RM}=$ raw milk. $\mathrm{PM}=$ pasteurized milk. $-=$ not present. Figures in bold represent the most abundantly isolated species. 


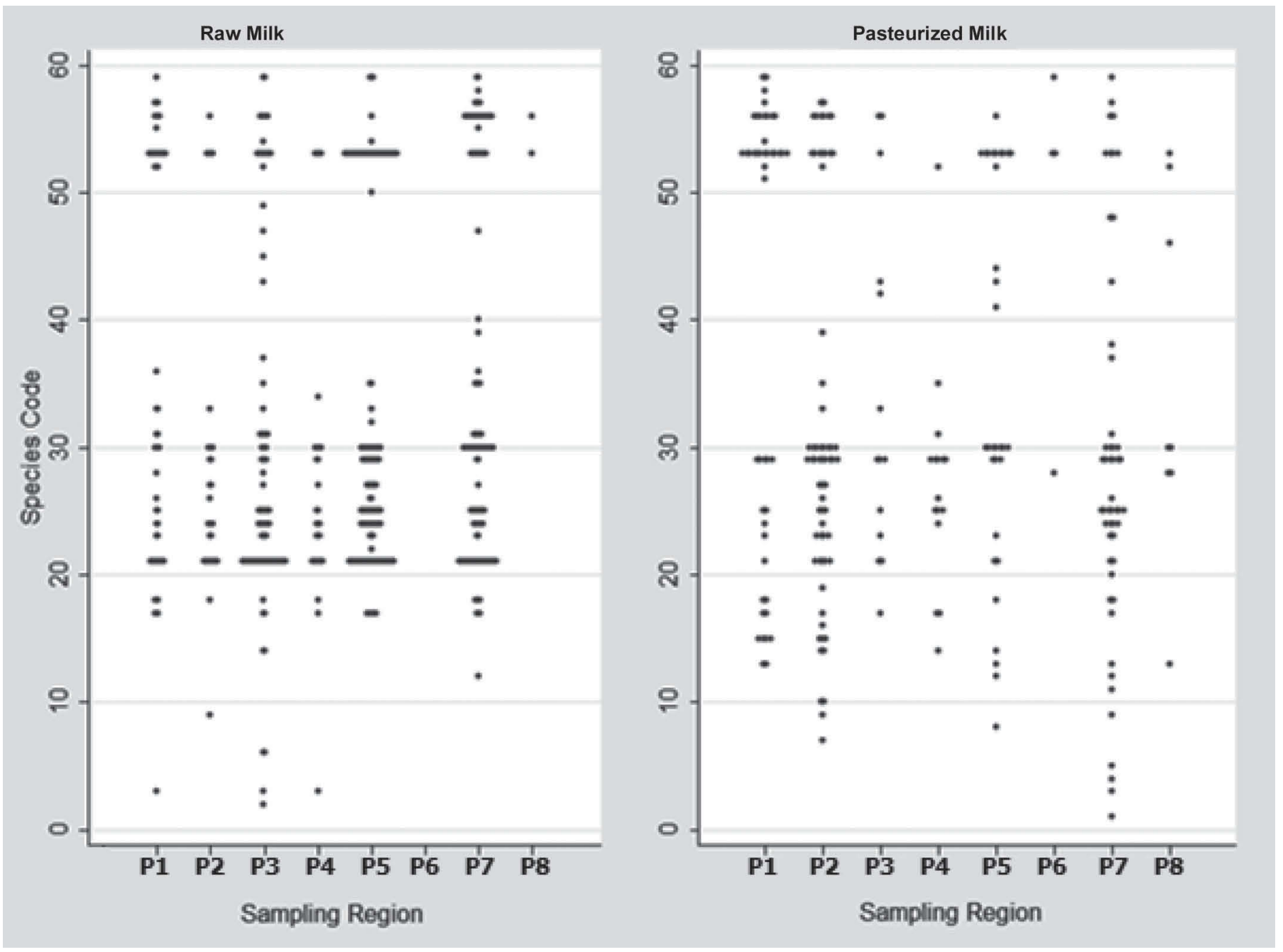

Figure 2. Distribution of Enterobacteriaceae and other bacterial species $(\mathrm{n}=729)$ from raw and pasteurized producer-distributor bulk milk from 8 different provinces in South Africa (P1-P8). Isolated species were coded 1 to 59. Width of the band represents the abundance of a particular species in the province. Species names for the dominant Enterobacteriaceae species are given in Table 1.

E. coli isolates can be as a result of restricted use of these agents in livestock production. Hence, the resistant determinants are lost over time without exposure to the drugs (Prescott et al., 2000). Approximately $60 \%(\mathrm{n}=89)$ of the antibiotic-resistant isolates were confirmed as multidrug resistant (MDR). The most prevalent MDR patterns were resistant to 2 and 3 of the antibiotic agents; however, more than $3 \%$ of isolates in provinces $\mathrm{P} 2$ and $\mathrm{P} 3$ exhibited MDR resistance to either 8 or 9 antibacterial agents. The highest number of phenotypes was observed for single antibiotic cephalothin $(15.7 \%)$ followed by oxytetracycline $(5 \%)$. Province P5 had the highest phenotypes that were resistant to cephalothin. Cephalothin was found in all MDR phenotypes observed. Provinces P3, P5, and P7 had the highest diversity of the MDR phenotypes for the antibiotics. Escherichia coli may develop multidrug resistance either independently and simultaneously, or co-selection of resistance factors by the organism (Sayah et al., 2005). High resistance of the E. coli isolates to cephalothin ( $51 \%$ isolates), neomycin $(34 \%$ isolates), ampicillin (24\% isolates), amoxicillin (23\% isolates), and oxytetracycline (17\% isolates) suggest the exposure of the isolates to the antibiotics. These antibiotics belong to commonly used classes of antibiotics including cephalosporins, tetracyclines, aminoglycosides, and penicillins in SA for treatment, prophylaxis, and as growth promoters in food-producing animals (Moyane et al., 2013). Kim et al. (2007) suggested use of antibiotics in treatment of cattle mastitis as a factor influencing increased prevalence of antibiotic-resistant pathogens though consensus is lacking concerning the link between drug usage and subsequent resistance in bacteria. Human food safety concerns has been raised 


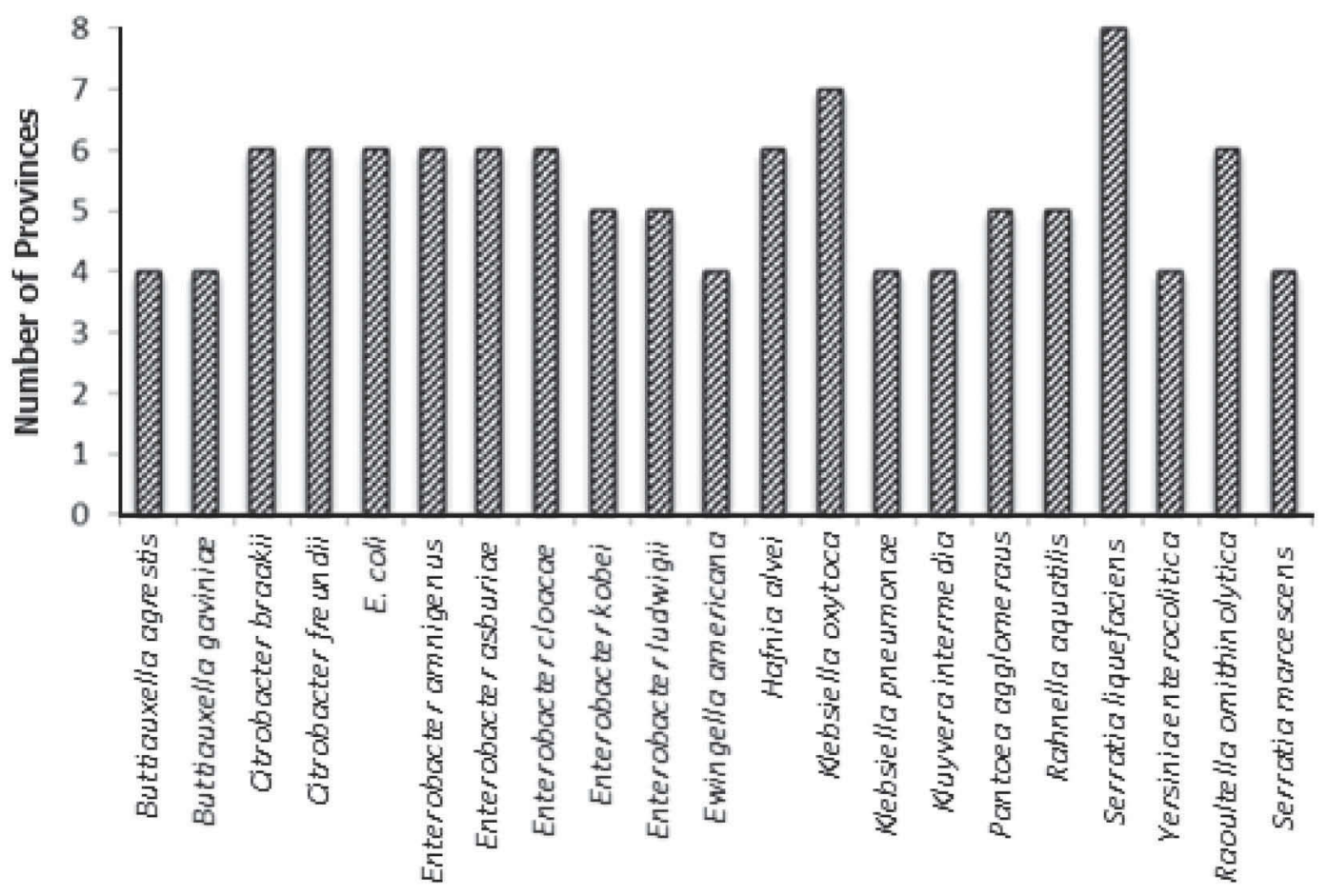

\section{Enterobacteriaceae species}

Figure 3. Frequency of dominant Enterobacteriaceae and other bacterial species isolated from raw and pasteurized producer-distributor bulk milk from 8 provinces in South Africa.

in cases where drug resistance bacteria is isolated in food because there is a potential transfer of resistance foodborne pathogens to humans through the food chain (Moyane et al., 2013). The highest resistance from the $E$. coli isolates in this study was noted in $\beta$-lactam antibiotics. $\beta$-Lactam antibiotics have low toxicity, a

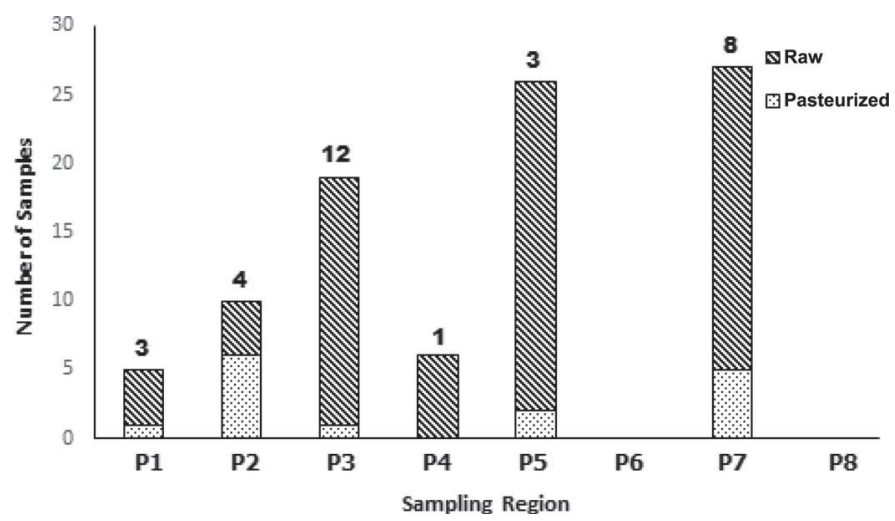

Figure 4. Number of samples that tested positive for Escherichia coli from raw and pasteurized producer-distributor bulk milk from the 8 provinces in South Africa (P1-P8). Figures above the graphs represent number of $E$. coli isolates that tested positive for either stx 1 or stx2. factor that has resulted in overuse of these drugs within animal husbandry and the medical fraternity (Moyane et al., 2013). Few studies have noted Enterobacteriaceae resistance to $\beta$-lactam antibiotic in milk samples; however, a study by Geser et al. (2012) reported resistance in E. coli from milk samples to CTX-M $\beta$-lactam antibiotics. Resistance to $\beta$-lactam antibiotic and the aminoglycosides was detected in $E$. coli isolates $(73 \%, \mathrm{n}$ $=121$ ) in PDBM sampled from all the provinces. This may be as a result of the $E$. coli from different provinces in SA being exposed to similar antibiotics despite the geographical difference.

Multiple antibiotic-resistant E. coli from provinces P2 and P3 had a higher prevalence than the other provinces. Multiple resistance to antibiotics by bacteria may be linked to acquire resistance either by crossresistance or co-selection of antibiotic resistance determinants (Baker-Austin et al., 2006). In cases of crossresistance in bacteria, a single resistance mechanism may confer resistance to an entire class of antibiotics and co-selection, meaning that bacteria can acquire additional resistance through mobile genetic elements such as plasmids in a large pool of antibiotic-resistant bacteria in the environment, ultimately resisting more than one antibiotic (Baker-Austin et al., 2006). For this 
Table 2. Prevalence of antibiotic-resistant Escherichia coli isolated from producer-distributor bulk milk in South Africa ${ }^{1}$

\begin{tabular}{|c|c|c|c|c|c|c|c|}
\hline Antibiotic & \multicolumn{6}{|c|}{ Province } & $\begin{array}{l}\text { Resistance } \\
(\mathrm{n}=121)\end{array}$ \\
\hline Cephalothin & 50 & 40 & 70 & 37.5 & 53.1 & 38.4 & 51.2 \\
\hline Nitroforantoin & 0 & 6.7 & 10 & 0 & 3.1 & 15.3 & 7.4 \\
\hline Amoxicillin & 40 & 6.7 & 36.7 & 12.5 & 21.9 & 15.3 & 23.1 \\
\hline Amikacin & 0 & 0 & 16.7 & 0 & 0 & 7.6 & 5.8 \\
\hline Norfloxacin & 0 & 6.7 & 6.7 & 0 & 0 & 0 & 2.5 \\
\hline Nalidixic acid & 0 & 0 & 6.7 & 0 & 0 & 0 & 1.7 \\
\hline Chloramphenicol & 0 & 0 & 10 & 0 & 0 & 3.8 & 3.3 \\
\hline Ampicillin & 20 & 6.7 & 46.7 & 12.5 & 25 & 15.3 & 24.8 \\
\hline
\end{tabular}

${ }^{1}$ Values in \% of resistant isolates. $\mathrm{n}$ is the number of E. coli isolates per province.

reason, PDBM in our study may serve as a reservoirs of antibiotic-resistant pathogens and can pose a food safety risk to the public as new antibiotic-resistant pathogenic Enterobacteriaceae strains can emerge through gene transfer.

Thirty-one $E$. coli isolates were positive for virulence genes stx1/stx2 and $38 \%(\mathrm{n}=121)$ were presumptive O157:H7. A total of 16,13 , and $12 \%(\mathrm{n}=121)$ of the E. coli isolates were presumptively positive for O157:H7 on CT-SMAC, CHROMagar O157, and BBL CHROMagar STEC agar, respectively. Out of the 46 isolates that were presumptively positive for $\mathrm{O} 157: \mathrm{H} 7$ E. coli, $10 \%$ showed a positive result on at least 2 of the media. The intimin (eae) gene was absent in all the E. coli isolates (Table 3). A proportion of $28 \%$ stx $1 /$ stx2 positive $E$. coli were isolated in pasteurized PDBM samples. Six presumptive O157:H7 E. coli isolates also harbored stx1/stx2 genes. Presence of virulence factors linked with EHEC in PDBM suggested the ability to cause Shiga toxin-related human infection and disease. Milkborne outbreaks and hospitalization caused by this E. coli pathotype have been well documented and reported around the world (CDC, 2005; Oliver et al., 2009; EFSA-ECDC, 2012).

Shiga toxin-producing E. coli were present in 7 and $3 \%$ $(\mathrm{n}=258)$ of the raw and pasteurized PDBM samples, respectively. Several studies around the world have reported the presence of STEC only in raw milk samples in Italy $(5.7 \%, \mathrm{n}=123)$, the United States $(2.4 \%, \mathrm{n}=$ 228; Jayarao and Henning, 2001), and France (21\%, n $=205$; Perelle et al., 2007). The main route by which STEC enters the raw milk supply is through fecal contamination or intramammary secretions from infected cow udder (King et al., 2007).

The sensitivity and specificity of the media used for the identification of presumptive E. coli $\mathrm{O} 157: \mathrm{H} 7$ was not evaluated, though CT-SMAC showed the highest number of O157:H7 characteristic colony appearance. Manafi and Kremsmaier (2001) evaluated sensitivity and specificity of 4 different O157:H7 media, SMAC, RainbowAgar O157:H7, Biosynth Culture Medium O157:H7, and Fluorocult HC, and found Biosynth Culture Medium to be most sensitive media. However, they strongly recommended a confirmatory test either by immunological or PCR method for suspect EHEC colony, irrespective of whatever combination of media was used.

Identification of stx genes in presumptive O157:H7 from PDBM in SA demonstrates that this milk may present a risk to public health. Escherichia coli O157:H7 is of great significance to foodborne diseases because of its high virulence (it can cause disease at a dose of

Table 3. Occurrence of presumptive O157:H7 strains and virulence factors (stx1, stx2) in Escherichia coli isolates from raw and pasteurized producer-distributor bulk milk in South Africa

\begin{tabular}{llcc}
\hline Province & O157:H7 \% & stx1/stx2 $\%$ & $\begin{array}{c}\text { Total number of } \\
\text { E. coli isolates }\end{array}$ \\
\hline P1 & 40.0 & 30.0 & 10 \\
P2 & 53.3 & 26.7 & 15 \\
P3 & 50.0 & 40.0 & 30 \\
P4 & 14.2 & 14.2 & 7 \\
P5 & 12.5 & 9.2 & 32 \\
P7 & 51.8 & 29.6 & 27 \\
Total number of isolates & $46(38.0 \%)$ & $31(25.6 \%)$ & 121 \\
\hline
\end{tabular}


5-50 cells; Farrokh et al., 2013). Prevalence of STEC O157:H7 in bulk milk samples in our study $(2 \%, \mathrm{n}=$ 258 ) was in the range of studies, which worked on similar milk, carried out in US [0.02\%, n $=859$ (Karns et al., 2007); 2.4\%, $\mathrm{n}=248$ (Jayarao et al., 2006)], Greek $(0.7 \%, \mathrm{n}=950$; Solomakos et al., 2009), and Australian (varied from 1-3\%; DairyAustralia, 2006) milk. All presumptive O157:H7 E. coli from PDBM that harbored sxt1, stx2, or both lacked the eae gene. This is contrary to other studies that noted an association between stx and eae genes in E. coli (Omisakin et al., 2003). The EHEC O157:H7 strain contains a locus of enterocyte effacement that is characterized by the presence of either eae, stx1, stx2 genes, or a combination of all 3 (Karns et al., 2007). Pathogenic E. coli lacking the eae gene has been reported to use other adhesion factors for attachment and pathogenicity (Doulgeraki et al., 2011). In findings similar to our study, STEC isolates from raw milk (44 isolates) did not harbor the eae gene (Farzan et al. (2012). The $80 \%(\mathrm{n}=31)$ of $s t x$-positive E. coli that were not O157:H7 suggested that the PDBM was also contaminated with emerging non-O157:H7 EHEC strains. Non-O157 E. coli pathotypes have been well documented in foodborne outbreaks that include milk and milk products around the world (Constantiniu, 2002). Karns et al. (2007) reported a higher prevalence in non-O157 EHEC than O157:H7 and other serotypes in bulk tank milk. Escherichia coli strains belonging to other serogroups (diarrheagenic) of public health concern may therefore pose a health risk in PDBM in SA.

In both raw and pasteurized PDBM, $58 \%$ of stx1/ stx2-positive E. coli was resistant to at least one antibiotic that was tested. Multi-drug resistance to at least 2 antibiotics was recorded in $38 \%(\mathrm{n}=31)$ of the stx1/stx2-positive isolates. More than $50 \%$ of the stx1/ stx2-positive isolates were resistant to cephalothin, a $\beta$-lactam first-generation drug. Result of the 2-sided Fisher's test revealed no significant correlation between antibiotic resistance and the presence of the stx1/stx2 gene. The dissemination of resistance is associated with genetic mobile elements such as pathogenicity islands that may also carry virulence determinants (Da Silva and Mendonça, 2012). Apart from virulence traits and antibiotic resistance genes being on the same genetic island such as plasmids, E. coli can also acquire virulence factor-encoding prophase (on chromosomal DNA) or plasmid-bearing antibiotic resistance factors (Rasko et al., 2011).

We also isolated STEC (2 isolates) that were resistant to quinolones in PDBM from the current study. Quinolone resistance are reported to have an inverse relationship with virulence genes. Resistance to the quinolones is mediated by point mutation in DNA gyrases and topoisomerases (Da Silva and Mendonça, 2012).
Most researchers have argued against the use of antibiotics such as quinolone in treatment of STEC-infected patients because of increased risk of hemolytic uremic syndrome (Muniesa et al., 2012). In this current study, prevalence of potential pathogenic EHEC that have drug resistance capacity, and also the possibility of the organisms to grow under improper storage, can present a significant public health risk, especially to vulnerable members of the community.

\section{Hierarchical Cluster Analysis}

Five main clusters (A to E) were observed from the E. coli dendrogram (Figure 5). The E. coli isolates were further subdivided into 8 sub-clusters defined by greater than $75 \%$ similarity which was equivalent to 1.5 , a distance considered as demarcating similar strains. Isolates within the 5 main clusters grouped irrespective of the province they were isolated. Group A consisted of isolates that emanated from 5 provinces; however, isolates from province P5 $(40 \%, \mathrm{n}=22)$ were dominant. All the 5 main clusters (A to E) observed contained at least one isolate from the 6 different provinces. The 5 main cluster groups contained at least $4 \mathrm{E}$. coli isolates that had been found to carry stx1/stx2 genes and came from different geographical locations. Isolates from P5 were found in all the sub-clusters. However, isolates from province P3 and P7 formed at least $80 \%$ of isolates from sub-clusters C5 and C8. Sub-cluster C4 was the biggest group consisting of $21 \%(\mathrm{n}=121)$ of the $E$. coli isolates, which were representative isolates from all 6 provinces. This group consisted of isolates that previously had common resistance to cephalothin, neomycin, ampicillin, amoxicillin, and oxytetracycline. No particular trend was observed with respect to origin of the isolates. The isolates grouped irrespective of the origin, indicating that isolates from different provinces were related. Some of the isolates from certain provinces were found in all the cluster groups, which indicates high genetic diversity among the isolates and wide distribution despite spatial differences in the milk sources. High genetic diversity of $E$. coli has been noted in isolates from human, animal, food, and the environment (Aslam et al., 2003; Apun et al., 2006; van Elsas et al., 2011). The high genetic diversity in E. coli could be attributed to its versatility and high degree of genomic plasticity, via gene loss or gain and through lateral gene transfer (Rasko et al., 2008). Internationally standardized phage typing, subtyping of stx and eae genes, and molecular fingerprinting using pulsed-field gel electrophoresis or repetitive extragenic palindromic (REP)-PCR have been used in studying epidemiological relationships and diversity among $E$. coli pathotypes (Beutin et al., 2002). However, recent developments in 
NTULI ET AL.

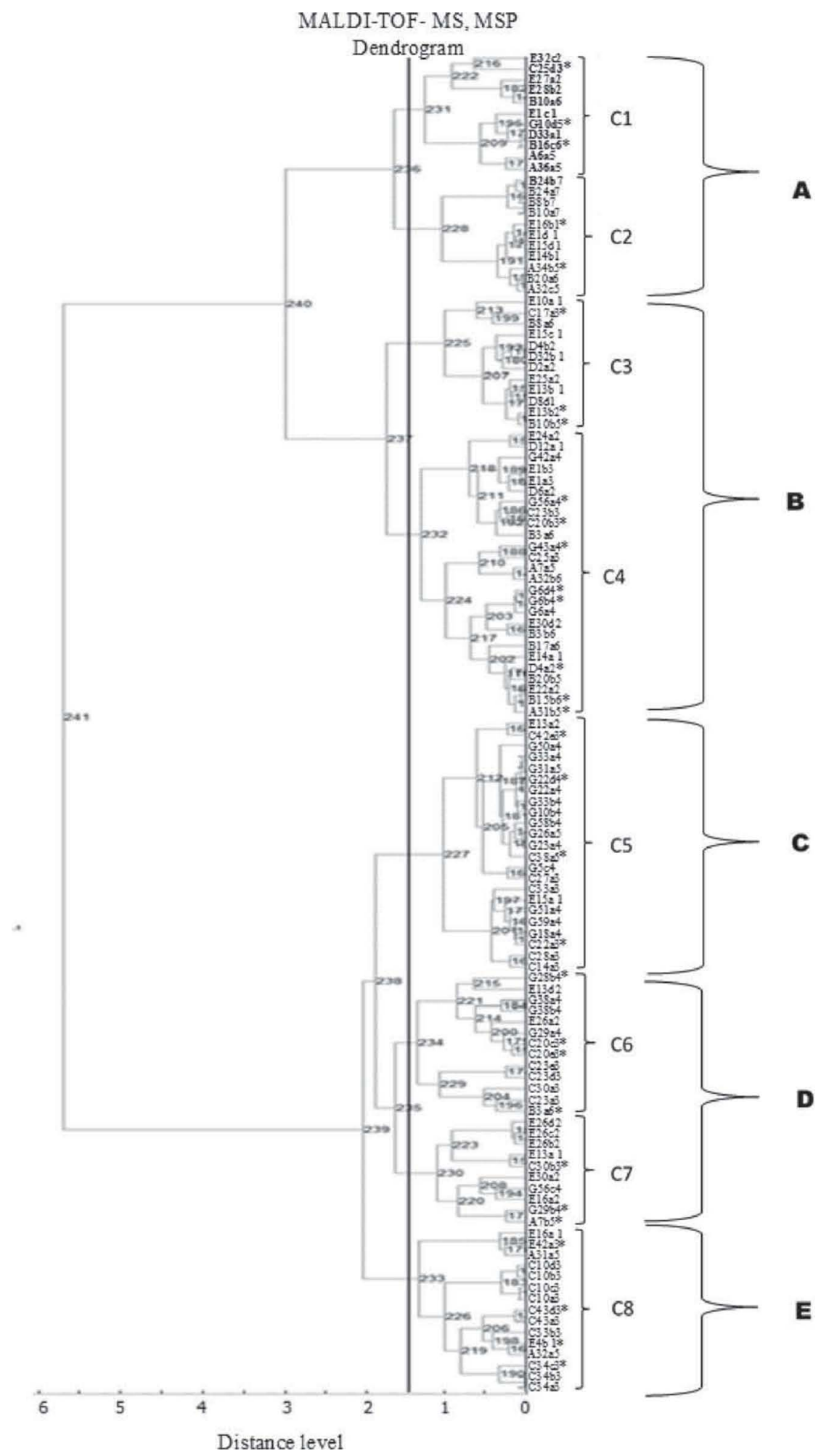

Figure 5. Two-dimensional hierarchical cluster analysis dendrogram for 121 Escherichia coli isolates from producer-distributor bulk milk in South Africa. Capital letters represent the different geographical provinces, and numbers with small letters represent different strains. The vertical line at 1.5 distance level represents the minimum similarity considered to be the highest point that distinct strains were identified ( $>75 \%$ similarity). Cluster groups under distance level 1.5 were considered to be distinct strains. Major brackets enclose the 5 super clustering groups (A to E), and minor brackets enclose the sub-clusters (C1 to C8). Provinces were labeled as follows: P1 (A), P2 (B), P3 (C), P4 (D), P5 (E), P6 (F), P7 (G), and P8 (H). Isolates with the asterisk were positive for stx1/stx2. MALDI-TOF-MS, MSP = matrix-assisted laser desorption/ ionization time-of-flight MS, main spectrum profile. 
MS show that its accuracy in identification compares well $(>80 \%)$ to conventional tools such as molecular techniques and analytical profile index (API) systems and have made it possible to use whole-cell MALDITOF MS in elucidating relationships among bacteria isolates from food and the environment (Risch et al., 2010; Arinto-Garcia et al., 2015). Albeit originating from different provinces, STEC from PDBM in the current study revealed genetic relatedness by grouping into unique clusters. Clusters with $E$. coli isolates that had

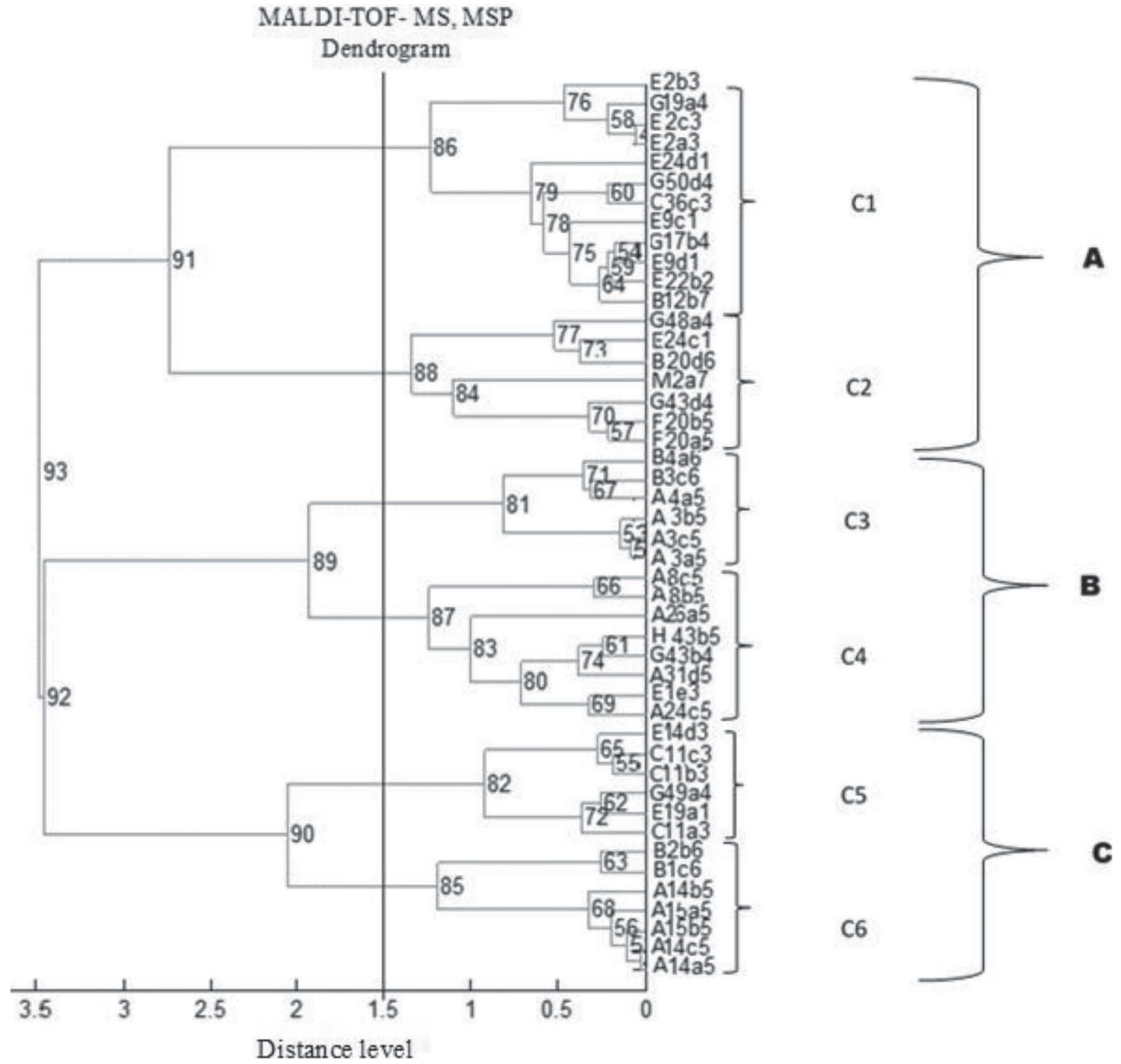

Figure 6. Two-dimensional hierarchical cluster analysis dendrogram for 47 Serratia liquefaciens isolates from producer-distributor bulk milk in South Africa. Capital letters represent the different geographical provinces, whereas numbers with small letters represent different strains. The vertical line at the 1.5 distance level represents the minimum similarity considered to be the highest point at which distinct strains were identified ( $>75 \%$ similarity). Cluster groups under distance level 1.5 were considered to be distinct strains. Major brackets enclose the 3 super clustering groups (A, B, and C), and minor brackets enclose the sub-clusters (C1 to C6). Provinces were labeled as follows: P1 (A), P2 (B), P3 (C), P4 (D), P5 (E), P6 (F), P7 (G), and P8 (H). MALDI-TOF-MS, MSP = matrix-assisted laser desorption/ionization time-of-flight MS, main spectrum profile. 


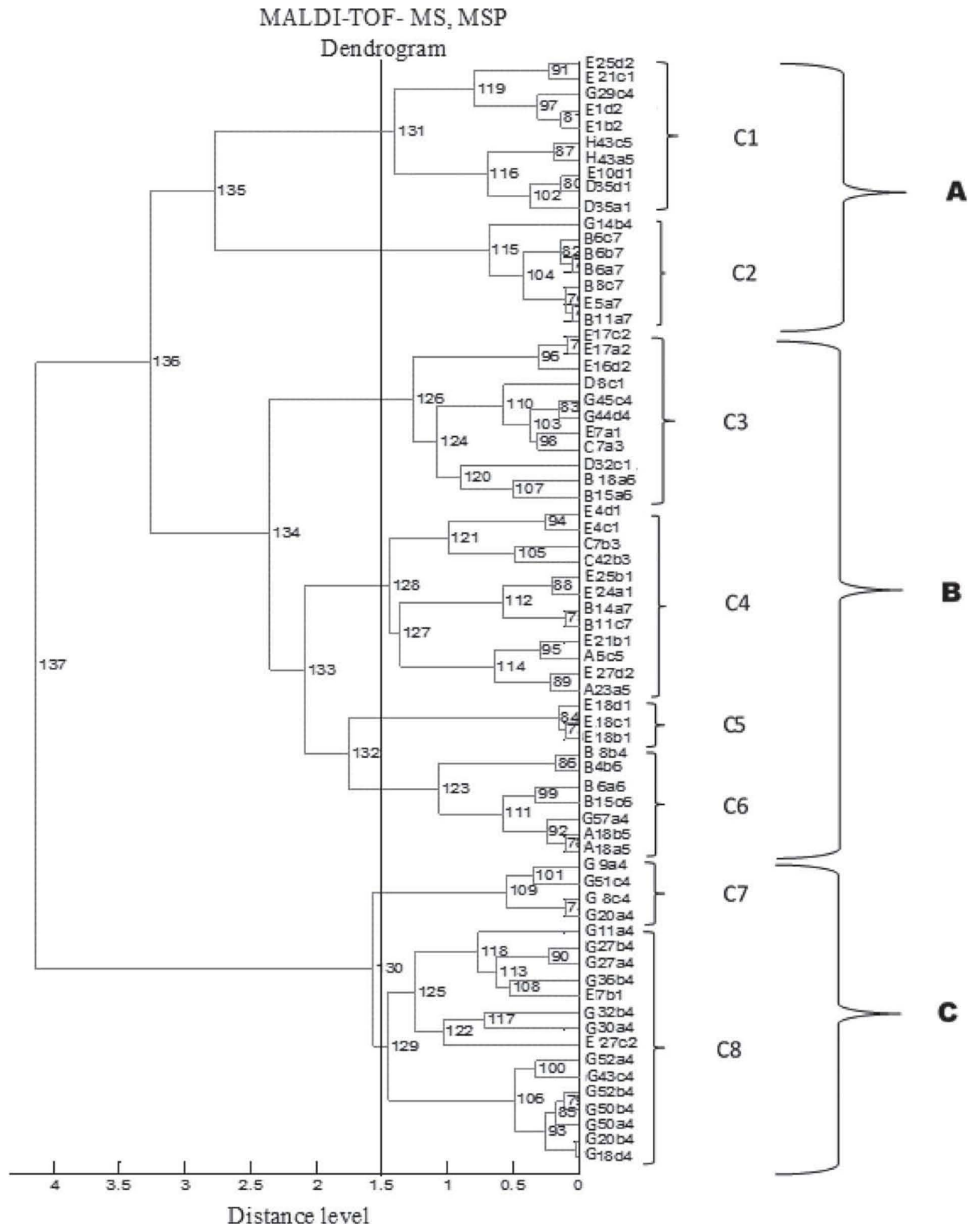

Figure 7. Two-dimensional hierarchical cluster analysis dendrogram for 70 Klebsiella oxytoca isolates from producer-distributor bulk milk in South Africa. Capital letters represent the different geographical provinces, and numbers with small letters represent different strains. The vertical line at 1.5 distance level represents the minimum similarity considered to be the highest point at which distinct strains were identified (>75\% similarity). Cluster groups under distance level 1.5 were considered to be distinct strains. Major brackets enclose the 3 super clustering groups (A, B, C), and minor brackets enclose the sub-clusters (C1 to C8). Provinces were labeled as follows: P1 (A), P2 (B), P3 (C), P4 (D), P5 (E), P6 (F), P7 (G), and P8 (H). MALDI-TOF-MS, MSP = matrix-assisted laser desorption/ionization time-of-flight MS, main spectrum profile. 
common antibiotic resistance patterns, even though they came from different regions, revealed the possibility of common antibiotic use in different provinces in SA (Da Silva and Mendonça, 2012).

Serratia liquefaciens and $K$. oxytoca were clustered because of their high occurrence and frequency of isolation in all the 8 provinces (Figure 3) and also their significance in food safety as opportunistic pathogenic and food spoilage organisms. Serratia liquefaciens strains showed 3 main distinct clusters (A, B, and C) and 6 sub-clusters ( $\mathrm{C} 1$ to $\mathrm{C} 6$ ) from the 8 provinces S. liquefaciens isolates were distributed irrespective of origin in all 3 main clusters (Figure 6). Isolates from $\mathrm{P} 1$ were found in sub-clusters $\mathrm{C} 2, \mathrm{C} 3, \mathrm{C} 4$, and $\mathrm{C} 6$, and they also formed $70 \%$ of the members of the sub-cluster groups C3 and C6. Sub-cluster group C1 was the biggest group, which consisted of $25 \%(\mathrm{n}=47)$ of the $S$. liquefaciens isolates, and the majority of the isolates in C1 came from province P5. Sub-clusters from the S. liquefaciens dendrogram consisted of isolates from provinces that are in close geographic proximity.

A 2-dimensional hierarchical cluster analysis for Klebsiella oxytoca showed 8 sub-clusters from 3 distinct main clusters (A, B, and $\mathrm{C}$ ). Isolates within the main cluster groups A and B were grouped irrespective of the geographical source. Cluster group B contained 4 sub-clusters with isolates mostly from P2 (Figure 7). Isolates from P7 formed $90 \%$ of the members of cluster group C. Sub-cluster C8 was the biggest, consisting of $21 \%$ of the $K$. oxytoca isolates, and $86 \%(\mathrm{n}=15)$ were from province $\mathrm{P} 7$. Isolates from province P5 were found in all the sub-clusters. Isolates originating from provinces in close proximity grouped together into subclusters.

Serratia liquefaciens and $K$. oxytoca isolates also showed no particular trend with respect to origin of the isolates. The isolates, like in E. coli cluster analysis, grouped irrespective of the origin, indicating high genetic diversity as well. Due to genomic plasticity of Enterobacteriaceae through lateral gene transfer, plasmid-encoding genetic determinants give rise to genetic and ecological diversity in this family of bacteria (Brisse and Verhoef, 2001; Iguchi et al., 2014). Iguchi et al. (2014) characterized genetic diversity of Serratia spp. using complete genome sequences and found a remarkable intra-species genetic diversity, both at the sequence level and with regard to genome flexibility, which may reflect the diversity in members of this species. Brisse and Verhoef (2001) noted a high degree of genetic heterogeneity and phylogenetic diversity of $K$. oxytoca from 120 clinical isolates using randomly amplified polymorphic DNA analysis. The authors noted that molecular techniques such as randomly amplified polymorphic DNA and 16S rRNA PCR have limitations in deducing the strain relationship of Enterobacteriaceae species. Such shortcomings can be overcome by use of MALDI-TOF MS. The MALDI-TOF MS techniques compare well with minimal limitations in bacteria characterization (Maja et al., 2013), source tracking (Siegrist et al., 2007), and strain relationship (Pignone et al., 2006) between isolates from food and the environment. Based on this study, the analysis of level of diversity among strains originating from different locations using MALDI-TOF MS can be helpful in typing a possible clonal relationship among Enterobacteriaceae strains and to monitoring the pathway of transmission of pathogenic strains that may pose a threat to public health and also the spoilage microbiota in food.

\section{CONCLUSIONS}

This study reports poor microbiological quality characterized by the occurrence of high microbial counts, which may reduce shelf life and can be a reservoir of pathogenic bacteria that potentially pose public health risks in PDBM. A wide diversity of Enterobacteriaceae species belonging mostly to spoilage microbiota was detected in PDBM. Considerable genetic diversity was found among the E. coli, S. liquefaciens, and K. oxytoca strains. We detected multidrug-resistant pathogenic $E$. coli in both raw and pasteurized retail PDBM, which is a cause of concern because these strains are a potential source of antimicrobial-resistant foodborne pathogens to humans through the food chain. These findings call for further assessment of the potential risk posed to public health by the milkborne pathogens through quantitative microbial risk assessment as a prerequisite to formulation of situation specific mitigation strategies.

\section{ACKNOWLEDGMENTS}

The authors thank Milk South Africa (Pretoria, Republic of South Africa) for funding the project.

\section{REFERENCES}

Aijuka, M., G. Charimba, C. J. Hugo, and E. M. Buys. 2015. Characterization of bacterial pathogens in rural and urban irrigation water. J. Water Health 13:103-117.

Apun, K., P. Chang, E. Sim, and V. Micky. 2006. Clonal diversity of Escherichia coli isolates from marketed beef in East Malaysia. World J. Microbiol. Biotechnol. 22:661-667.

Arinto-Garcia, R., M. D. Pinho, J. A. Carriço, J. Melo-Cristino, and M. Ramirez. 2015. Comparing matrix-assisted laser desorption ionization-time of flight mass spectrometry and phenotypic and molecular methods for identification of species within the Streptococcus anginosus group. J. Clin. Microbiol. 53:3580-3588.

Aslam, M., F. Nattress, G. Greer, C. Yost, C. Gill, and L. McMullen. 2003. Origin of contamination and genetic diversity of Escherichia coli in beef cattle. Appl. Environ. Microbiol. 69:2794-2799. 
Baker-Austin, C., M. S. Wright, R. Stepanauskas, and J. McArthur. 2006. Co-selection of antibiotic and metal resistance. Trends Microbiol. 14:176-182.

Baylis, C., M. Uyttendaele, H. Joosten, and A. Davies. 2011. The Enterobacteriaceae and their significance to the food industry. ILSI Europe, Brussels, Belgium. www.ilsi.eu.

Beutin, L., S. Kaulfuss, T. Cheasty, B. Brandenburg, S. Zimmermann, K. Gleier, G. A. Willshaw, and H. R. Smith. 2002. Characteristics and association with disease of two major subclones of Shiga toxin (Verocytotoxin)-producing strains of Escherichia coli (STEC) O157 that are present among isolates from patients in Germany. Diagn. Microbiol. Infect. Dis. 44:337-346.

Beutin, L., G. Krause, S. Zimmermann, S. Kaulfuss, and K. Gleier 2004. Characterization of Shiga toxin-producing Escherichia col strains isolated from human patients in Germany over a 3-year period. J. Clin. Microbiol. 42:1099-1108.

Boerlin, P., S. Eugster, F. Gaschen, R. Straub, and P. Schawalder. 2001. Transmission of opportunistic pathogens in a veterinary teaching hospital. Vet. Microbiol. 82:347-359.

Brisse, S., and J. Verhoef. 2001. Phylogenetic diversity of Klebsiella pneumoniae and Klebsiella oxytoca clinical isolates revealed by randomly amplified polymorphic DNA, gyrA and parC genes sequencing and automated ribotyping. Int. J. Syst. Evol. Microbiol. 51:915-924.

CDC. 2005. Escherichia coli O157:H7 Infection Associated with Drinking Raw Milk-Washington and Oregon, November-December 2005. CDC, Atlanta, GA.

CDC. 2008. Outbreak of Listeria monocytogenes infections associated with pasteurized milk from a local dairy-Massachusetts, 2007. MMWR Morb. Mortal. Wkly. Rep. 57:1097-1100.

CDC. 2013. Antibiotic Resistance Threats in the United States, 2013 US Department of Health and Human Services, CDC, Atlanta, GA

Cherkaoui, A., J. Hibbs, S. Emonet, M. Tangomo, M. Girard, P. Francois, and J. Schrenzel. 2010. Comparison of two matrix-assisted laser desorption ionization-time of flight mass spectrometry methods with conventional phenotypic identification for routine identification of bacteria to the species level. J. Clin. Microbiol. 48:1169-1175.

Chmielewski, R., and J. Frank. 2003. Biofilm formation and control in food processing facilities. Compr. Rev. Food Sci. Food Saf. 2:22-32.

CLSI. 2011. Performance standards for antimicrobial susceptibility testing, 21st informational supplement. CLSI document M100S21. Clinical and Laboratory Standards Institute, Wayne, PA.

Constantiniu, S. 2002. Escherichia coli enterohemoragic-An emerged pathogen of human infections Part II. Non-O157 Escherichia coli enterohemorrhagic. J. Prev. Med 10:57-73.

Coque, T., F. Baquero, and R. Canton. 2008. Increasing prevalence of ESBL-producing Enterobacteriaceae in Europe. Euro surveillance: European Communicable Disease Bulletin 13:5437-5453.

Da Silva, G. J., and N. Mendonça. 2012. Association between antimicrobial resistance and virulence in Escherichia coli. Virulence $3: 18-28$.

DairyAustralia. 2006. Situation and outlook. Accessed Apr. 10, 2016. www.dairyaustralia.com.

Doulgeraki, A. I., S. Paramithiotis, and G.-J. E. Nychas. 2011. Characterization of the Enterobacteriaceae community that developed during storage of minced beef under aerobic or modified atmosphere packaging conditions. Int. J. Food Microbiol. 145:77-83.

Dubois, D., D. Leyssene, J. P. Chacornac, M. Kostrzewa, P. O. Schmit, R. Talon, R. Bonnet, and J. Delmas. 2010. Identification of a variety of Staphylococcus species by matrix-assisted laser desorption ionization-time of flight mass spectrometry. J. Clin. Microbiol. 48:941-945.

EFSA. 2015. Scientific opinion on the public health risks related to the consumption of raw drinking milk. EFSA Journal 13:3940.

EFSA-ECDC. 2012. Scientific Report of EFSA and ECDC: The European Union Summary report on trends and sources of zoonoses, agents and food-borne outbreaks in 2010. EFSA J. 10:2597.
Eneroth, Å., S. Ahrné, and G. Molin. 2000. Contamination of milk with Gram-negative spoilage bacteria during filling of retail containers. Int. J. Food Microbiol. 57:99-106.

Erskine, R., R. Walker, C. Bolin, P. Bartlett, and D. White. 2002. Trends in antibacterial susceptibility of mastitis pathogens during a seven-year period. J. Dairy Sci. 85:1111-1118.

Farrokh, C., K. Jordan, F. Auvray, K. Glass, H. Oppegaard, S. Raynaud, D. Thevenot, R. Condron, K. De Reu, and A. Govaris 2013. Review of Shiga-toxin-producing Escherichia coli (STEC) and their significance in dairy production. Int. J. Food Microbiol. 162:190-212.

Farzan, R., E. Rahimi, and H. Momtaz. 2012. Virulence properties of Shiga toxin-producing Escherichia coli isolated from Iranian raw milk and dairy products. Slov Vet. Res. 49:159-166.

Foodstuffs, Cosmetics and Disinfectants Act. 1997. (54). 1972. Government Printer 1997 Foodstuff, Cosmetics and Disinfectants Act, No. 54 of 1972: Regulations relating to milk and milk products, No. R.1555. Government Gazette No. 18439, 21 November 1997, 4-29.

Geser, N., R. Stephan, and H. Hächler. 2012. Occurrence and characteristics of extended-spectrum $\beta$-lactamase (ESBL) producing Enterobacteriaceae in food producing animals, minced meat and raw milk. BMC Vet. Res. 8:21.

Iguchi, A., Y. Nagaya, E. Pradel, T. Ooka, Y. Ogura, K. Katsura, K. Kurokawa, K. Oshima, M. Hattori, and J. Parkhill. 2014. Genome evolution and plasticity of Serratia marcescens, an important multidrug-resistant nosocomial pathogen. Genome Biol. Evol. 6:2096-2110.

ISO. 1997. International Standards Organisation (ISO 707:1997) Milk and milk products - Guidance on sampling. ISO.

Iweriebor, B. C., C. J. Iwu, L. C. Obi, U. U. Nwodo, and A. I. Okoh. 2015. Multiple antibiotic resistances among Shiga toxin producing Escherichia coli $\mathrm{O} 157$ in feces of dairy cattle farms in Eastern Cape of South Africa. BMC Microbiol. 15:213.

Jayarao, B. M., S. C. Donaldson, B. A. Straley, A. A. Sawant, N. V. Hegde, and J. Brown. 2006. A survey of foodborne pathogens in bulk tank milk and raw milk consumption among farm families in Pennsylvania. J. Dairy Sci. 89:2451-2458.

Jayarao, B. M., and D. Henning. 2001. Prevalence of foodborne pathogens in bulk tank milk. J. Dairy Sci. 84:2157-2162.

Karns, J. S., J. S. Van Kessel, B. J. McClusky, and M. L. Perdue. 2007. Incidence of Escherichia coli $\mathrm{O} 157: \mathrm{H} 7$ and E. coli virulence factors in US Bulk tank milk as determined by polymerase chain reaction. J. Dairy Sci. 90:3212-3219.

Kerényi, M., H. E. Allison, I. Bátai, A. Sonnevend, L. Emödy, N. Plaveczky, and T. Pál. 2005. Occurrence of hlyA and sheA genes in extraintestinal Escherichia coli strains. J. Clin. Microbiol. 43:29652968 .

Kim, J. S., E. Kuk, K. N. Yu, J.-H. Kim, S. J. Park, H. J. Lee, S. H. Kim, Y. K. Park, Y. H. Park, and C.-Y. Hwang. 2007. Antimicrobial effects of silver nanoparticles. Nanomedicine 3:95-101.

King, N., R. Lake, P. Cressey, and A. Hudson. 2007. Risk profile: Shiga-toxin producing Escherichia coli in raw milk. MPI Technical Paper No: 2014/14. Ministry for Primary Industries. New Zealand Food Safety Authority (NZFSA) and the Ministry of Agriculture and Forestry (MAF).

Kurwijila, L., A. Omore, S. Staal, and N. Mdoe. 2006. Investigation of the risk of exposure to antimicrobial residues present in marketed milk in Tanzania. J. Food Prot. 69:2487-2492.

Ledenbach, L. H., and R. T. Marshall. 2010. Microbiological spoilage of dairy products. Pages 41-67 in Compendium of the Microbiological Spoilage of Foods and Beverages. Springer, New York, NY.

Lin, C.-M., H.-F. Kung, Y.-L. Huang, C.-Y. Huang, Y.-C. Su, and Y.H. Tsai. 2012. Histamine production by Raoultella ornithinolytica in canned tuna meat at various storage temperatures. Food Contr. 25:723-727.

Lues, J., P. Venter, and H. Van der Westhuizen. 2003. Enumeration of potential microbiological hazards in milk from a marginal urban settlement in central South Africa. Food Microbiol. 20:321-326.

Lues, J. F. R., H. de Beer, A. Jacoby, K. E. Jansen, and K. Shale. 2010. Microbial quality of milk, produced by small scale farm- 
ers in a peri-urban area in South Africa. Afr. J. Microbiol. Res. 4:1823-1830.

Maja, T.-K., M. Gertjan, and H. Wim. 2013. Comparison between Rapid ID 32 Strep System, Matrix Assisted Laser Desorption Ionisation-Time of Flight Mass Spectrometry and 16S rRNA gene sequence analysis for the species identification of Enterococcus spp. isolated from water. Water Sci. Technol. Water Supply 13:13831389 .

Manafi, M., and B. Kremsmaier. 2001. Comparative evaluation of different chromogenic/fluorogenic media for detecting Escherichia coli $\mathrm{O} 157: \mathrm{H} 7$ in food. Int. J. Food Microbiol. 71:257-262.

Mazzeo, M. F., A. Sorrentino, M. Gaita, G. Cacace, M. Di Stasio, A. Facchiano, G. Comi, A. Malorni, and R. A. Siciliano. 2006. Matrix-assisted laser desorption ionization-time of flight mass spectrometry for the discrimination of food-borne microorganisms. Appl. Environ. Microbiol. 72:1180-1189.

Mercer, R. G., J. Zheng, R. Garcia-Hernandez, L. Ruan, M. G. Gänzle, and L. M. McMullen. 2015. Genetic determinants of heat resistance in Escherichia coli. Front. Microbiol. 6:932.

Miranda, J., M. Guarddon, B. Vázquez, C. Fente, J. Barros-Velazquez, A. Cepeda, and C. Franco. 2008. Antimicrobial resistance in Enterobacteriaceae strains isolated from organic chicken, conventional chicken and conventional turkey meat: A comparative survey. Food Contr. 19:412-416.

Moyane, J., A. Jideani, and O. Aiyegoro. 2013. Antibiotics usage in food-producing animals in South Africa and impact on human: Antibiotic resistance. Afr. J. Microbiol. Res. 7:2990-2997.

Muniesa, M., J. A. Hammerl, S. Hertwig, B. Appel, and H. Brüssow. 2012. Shiga toxin-producing Escherichia coli O104:H4: A new challenge for microbiology. Appl. Environ. Microbiol. 78:4065-4073.

Nornberg, M. F., R. S. Friedrich, R. D. Weiss, E. C. Tondo, and A. Brandelli. 2010. Proteolytic activity among psychrotrophic bacteria isolated from refrigerated raw milk. Int. J. Dairy Technol. 63:41-46.

O'Ferrall-Berndt, M. M. 2003. A comparison of selected public health criteria in milk from milk-shops and from a national distributor. J. S. Afr. Vet. Assoc. 74:35-40.

Oliver, S. P., K. J. Boor, S. C. Murphy, and S. E. Murinda. 2009. Food safety hazards associated with consumption of raw milk. Foodborne Pathog. Dis. 6:793-806.

Omisakin, F., M. MacRae, I. Ogden, and N. Strachan. 2003. Concentration and prevalence of Escherichia coli O157 in cattle feces at slaughter. Appl. Environ. Microbiol. 69:2444-2447.

Perelle, S., F. Dilasser, J. Grout, and P. Fach. 2007. Screening food raw materials for the presence of the world's most frequent clinical cases of Shiga toxin-encoding Escherichia coli O26, O103, O111, O145 and O157. Int. J. Food Microbiol. 113:284-288.

Pignone, M., K. M. Greth, J. Cooper, D. Emerson, and J. Tang. 2006. Identification of mycobacteria by matrix-assisted laser desorption ionization-time-of-flight mass spectrometry. J. Clin. Microbiol. 44:1963-1970.

Pinto, L., P. Poeta, S. Vieira, C. Caleja, H. Radhouani, C. Carvalho, M. Vieira-Pinto, P. Themudo, C. Torres, R. Vitorino, P. Domingues, and G. Igrejas. 2010. Genomic and proteomic evaluation of antibiotic resistance in Salmonella strains. J. Proteomics $73: 1535-1541$.

Prescott, J., J. Baggot, and R. Walker. 2000. Antimicrobial Therapy in Veterinary Epidemiology. Iowa State University Press, Ames.

Pyz-Łukasik, R., W. Paszkiewicz, M. Tatara, P. Brodzki, and Z. Bełkot. 2015. Microbiological quality of milk sold directly from producers to consumers. J. Dairy Sci.98:4294-4301.

Rankin, S., A. Christiansen, W. Lee, D. Banavara, and A. LopezHernandez. 2010. Invited review: The application of alkaline phos- phatase assays for the validation of milk product pasteurization. J. Dairy Sci. 93:5538-5551.

Rasko, D. A., M. Rosovitz, G. S. Myers, E. F. Mongodin, W. F. Fricke, P. Gajer, J. Crabtree, M. Sebaihia, N. R. Thomson, and R. Chaudhuri. 2008. The pangenome structure of Escherichia coli: Comparative genomic analysis of E. coli commensal and pathogenic isolates. J. Bacteriol. 190:6881-6893.

Rasko, D. A., D. R. Webster, J. W. Sahl, A. Bashir, N. Boisen, F. Scheutz, E. E. Paxinos, R. Sebra, C.-S. Chin, and D. Iliopoulos. 2011. Origins of the E. coli strain causing an outbreak of hemolytic-uremic syndrome in Germany. N. Engl. J. Med. 365:709-717.

Riley, L. W., E. Raphael, and E. Faerstein. 2013. Obesity in the United States-Dysbiosis from exposure to low-dose antibiotics? Front. Public Health 1:69.

Risch, M., D. Radjenovic, J. N. Han, M. Wydler, U. Nydegger, and L. Risch. 2010. Comparison of MALDI TOF with conventional identification of clinically relevant bacteria. Swiss Med. Wkly. 140:w13095.

Romano, I., L. Lama, B. Nicolaus, A. Gambacorta, and A. Giordano. 2005. Bacillus saliphilus sp. nov., isolated from a mineral pool in Campania, Italy. Int. J. Syst. Evol. Microbiol. 55:159-163.

SA. 2001 Act (54), (1972). South Africa: Regulations relating to milk and dairy products (updated). Government Printer, Pretoria, Republic of South Africa.

Sauer, S., A. Freiwald, T. Maier, M. Kube, R. Reinhardt, M. Kostrzewa, and K. Geider. 2008. Classification and identification of bacteria by mass spectrometry and computational analysis. PLoS One $3: \mathrm{e} 2843$.

Sayah, R. S., J. B. Kaneene, Y. Johnson, and R. Miller. 2005. Patterns of antimicrobial resistance observed in Escherichia coli isolates obtained from domestic-and wild-animal fecal samples, human septage, and surface water. Appl. Environ. Microbiol. 71:13941404.

Schroeder, C. M., J. Meng, S. Zhao, C. DebRoy, J. Torcolini, C. Zhao, P. F. McDermott, D. D. Wagner, R. D. Walker, and D. G. White. 2002. Antimicrobial resistance of Escherichia coli O26, O103, O111, O128, and O145 from animals and humans. Emerg. Infect. Dis. 8:1409-1414.

Siegrist, T. J., P. D. Anderson, W. H. Huen, G. T. Kleinheinz, C. M. McDermott, and T. R. Sandrin. 2007. Discrimination and characterization of environmental strains of Escherichia coli by matrixassisted laser desorption/ionization time-of-flight mass spectrometry (MALDI-TOF-MS). J. Microbiol. Methods 68:554-562.

Solomakos, N., A. Govaris, A. S. Angelidis, S. Pournaras, A. R. Burriel, S. K. Kritas, and D. K. Papageorgiou. 2009. Occurrence, virulence genes and antibiotic resistance of Escherichia coli $\mathrm{O} 157$ isolated from raw bovine, caprine and ovine milk in Greece. Food Microbiol. 26:865-871.

Swai, E., and L. Schoonman. 2011. Microbial quality and associated health risks of raw milk marketed in the Tanga region of Tanzania. Asian Pac. J. Trop. Biomed. 1:217-222.

Torkar, K. G., and S. G. Teger. 2008. The microbiological quality of raw milk after introducing the two day's milk collecting system. Acta Agric. Slov. 92:61-74.

van Elsas, J. D., A. V. Semenov, R. Costa, and J. T. Trevors. 2011. Survival of Escherichia coli in the environment: Fundamental and public health aspects. ISME J. 5:173-183.

Van Kessel, J., J. Karns, L. Gorski, B. McCluskey, and M. Perdue. 2004. Prevalence of Salmonellae, Listeria monocytogenes, and fecal coliforms in bulk tank milk on US dairies. J. Dairy Sci. 87:28222830.

Whitaker, J. R., A. G. Voragen, and D. W. Wong. 2003. Handbook of Food Enzymology. Marcel Dekker, New York, NY. 